\title{
Best-estimate simulation of a VVER MSLB core transient using the NURESIM platform codes
}

\author{
I. Spasov $^{a}$, S. Mitkov ${ }^{a}$, N.P. Kolev ${ }^{a,}{ }^{*}$, S. Sanchez-Cervera ${ }^{b}$, N. Garcia-Herranz ${ }^{b}$, A. Sabater ${ }^{b}$, D. Cuervo ${ }^{b}$, \\ J. Jimenez ${ }^{c}$, V.H. Sanchez ${ }^{c}$, L. Vyskocil ${ }^{\mathrm{d}}$ \\ ${ }^{a}$ Institute for Nuclear Research and Nuclear Energy, Bulgaria \\ ${ }^{\mathrm{b}}$ Universidad Politécnica de Madrid, Spain \\ ${ }^{\mathrm{c}}$ Karlsruhe Institute of Technology, Germany \\ ${ }^{\mathrm{d}}$ Ustav Jaderneho Vyzkumu Rez, Czech Republic
}

\section{A B S T R A C T}

\begin{abstract}
This paper summarizes the nodal level results from the VVER MSLB core simulation in the NURESAFE EU project. The main objective is to implement and verify new developments in the models and couplings of 3D core simulators for cores with hexagonal fuel assemblies. Recent versions of the COBAYA and DYN3D core physics codes, and the FLICA4 and CTF thermal-hydraulic codes were tested standalone and coupled through standardized coupling functions in the Salome platform. The MSLB core transient was analyzed in coupled code simulation of a core boundary condition problem derived from the OECD VVER MSLB benchmark. The impact of node sub-division and different core mixing models, as well as the effects of CFD computed core inlet thermal-hydraulic boundary conditions on the core dynamics were explored.
\end{abstract}

Keywords:

VVER MSLB

Core boundary condition problem

Nodal methods

Best-estimate simulation

\section{Introduction}

The analysis of main steam line break (MSLB) reactivity transients is a challenging task because of the strongly pronounced local 3D effects in the core and the reactor pressure vessel (RPV) and correspondingly the need for detailed modeling of both the neutronics and the coolant mixing. The VVER-1000 MSLB simulation has been subject of the OECD VVER-1000 Coolant Transient Benchmark - V1000CT-2 (Kolev et al., 2006). The analysis of the benchmark results indicated the potential for improving the quality of simulation through the use of enhanced models of the flow mixing and the 3D core dynamics.

This article presents the full-core nodal-level simulation results from the VVER MSLB work package in the NURESAFE EU project. As stated in the NURESAFE description of work (Chanaron, 2012; Chanaron et al., 2015) the main objective of the work on the VVER MSLB situation target was to develop and execute simulation schemes towards higher-resolution. Specific objectives were to test new developments in the nodal and pin-by-pin models and couplings for VVER applications, as well as CFD and CFD/system code simulation of the RPV with enhanced prediction capability. This paper concentrates on the nodal core models which can be

\footnotetext{
* Corresponding author.

E-mail address: npkolev@inrne.bas.bg (N.P. Kolev).
}

supplemented by pin-power reconstruction (PPR) and application of CFD computed core boundary conditions. The results from pin/ pin models, sub-channel thermal-hydraulic analysis and coupled COBAYA4/CTF pin-cell simulation of VVER core subsets will be subject of separate publications.

For the purposes of this study a core boundary condition problem with pre-calculated boundary conditions was derived from the OECD VVER MSLB benchmark. Validated COBAYA and DYN3D corephysics models with homogenized nodes were coupled to full-core FLICA4 or CTF thermal-hydraulic models. The core transient scenario was analyzed in coupled COBAYA3/FLICA4, COBAYA4/CTF and DYN3D/CTF simulations.

Special attention was paid to the effects of different flow mixing models in the RPV and the core. Time-dependent MSLB core boundary conditions (BC) were obtained in two variants: from CATHARE coarse-mesh RPV simulation (Spasov et al., 2010), and from CFD calculations for the down-comer and the lower plenum (Vyskocil, 2015). The corresponding vessel mixing models were qualified against Kozloduy- 6 data from a vessel mixing experiment conducted during the plant commissioning phase (Topalov et al., 2004; Kolev et al., 2007). The impact of CFD computed core boundary conditions on the $3 \mathrm{D}$ core dynamics was explored in comparative MSLB core calculations.

For multi-physics core simulation a wide-range multiparameter VVER MSLB cross-section library for homogenized 
nodes was generated (Petrov et al., 2015) using the APOLLO2 code (Sanchez, 2010; Santandrea et al., 2008). This library is supple mented by a multi parameter library of APOLLO2 computed pin by pin form functions for each node which allows DYN3D pin power reconstruction.

In the sections below a brief description of the codes and mod els used is given and the simulation results are discussed.

\section{Codes and models description}

For coupled core neutronic thermal hydraulic $(\mathrm{N} / \mathrm{TH})$ simula tion, recent versions of COBAYA, DYN3D, FLICA4 and CTF were used. The considered code couplings are COBAYA3/FLICA4, COBAYA4/CTF and DYN3D/CTF in Salome (http://www.salome platform.org/). CATHARE2 (Geffraye et al., 2011) and FLUENT (ANSYS Fluent, 2015) codes were used to solve the MSLB RPV boundary condition problem and to compute time dependent MSLB core BC, as discussed in paragraphs 4.2 and 5.3 below.

These codes and couplings, except for FLUENT, make part of the European NURESIM software platform (Chauliac et al., 2011 and Chanaron et al., 2015) which is a set of state of the art software devoted to the simulation of normal operation and design basis accidents of light water reactors: BWR, PWR, VVER. This platform currently includes 12 codes covering different physics: neutronics, thermal hydraulics, fuel thermo mechanics and relevant scales: local (sub channel or pin), fuel assembly, core and reactor system. Given their complementary features, the selected codes offer solu tions suitable for various situations.

\subsection{COBAYA code}

COBAYA is a multi scale 3D core simulator code developed by the Universidad Politecnica de Madrid (Cobaya team, 2015; Ahnert, 2015). It uses transport corrected multi group (MG) diffu sion approximation and performs steady state and transient calcu lations of light water reactors (LWR) for both Cartesian rectangular and hexagonal geometries. At the nodal level, the flux solver, called ANDES (Analytic Nodal Diffusion Equation Solver) (Lozano et al., 2008) uses the ACMFD (Analytic Coarse Mesh Finite Difference) method (Aragones et al., 2007; Garcia Herranz et al., 2002). ANDES can be used stand alone to perform nodal full core calculations, or as an accelerating module for the pin by pin solver. It has been numerically validated for a number of numerical benchmarks (Lozano et al., 2010). In hexagonal geometry, the code is capable of node sub division to 6 or 24 triangles per hexagon. In the pre sent study, 6 triangles per hexagon $(6 \mathrm{~N})$ and 30 axial nodes in the heated core were assumed. At the pin level, the multi group diffusion equation is solved using a FMFD (fine mesh finite difference) method (Herrero et al., 2009).

The COBAYA nodal core physics solver has been extensively benchmarked in the frame of EU projects. Recently a new version of the code, COBAYA4 has been released (Ahnert, 2015) which fea tures a fully renovated code architecture and improved capability of parallelization on multi core systems and graphical processing units (GPU). The code has been coupled with core thermal hydraulic codes in the Salome platform (see the paragraph on cou pling below).

\subsection{DYN3D code}

DYN3D is a 3D core simulator developed by the Helmholtz Zentrum Dresden Rossendorf. It solves the $2 \mathrm{G}$ diffusion equation with a nodal expansion method and performs steady state and transient core calculations of LWR with hexagonal and square fuel assemblies (Rohde et al., 2016). Recently a multi group nodal sol ver for hexagonal geometry and a multi group SP3 pin by pin sol ver for square lattices have been added. The code has been coupled with core TH codes in the Salome platform (see the paragraph on coupling below). In this study at the nodal level the VVER model assumes one node per hexagon and 30 axial nodes in the heated part of the core.

DYN3D is capable of nodal calculations with pin power recon struction in hexagonal geometry (Hádek et al., 2009; Hádek, 2012; Gomez et al., 2014). In the frame of NURESAFE a recent ver sion of the nodal/PPR calculation scheme using an APOLLO2 gener ated multi parameter library of pin by pin node power shapes (form functions) has been numerically validated vs. transport ref erence solutions for VVER mini cores (Hádek, 2016).

\subsection{Full core FLICA4 model}

FLICA4 (Toumi et al., 2000; Fillion et al., 2011a,b) is a 3D core thermal hydraulic code of CEA with sub channel capabilities. It is based on a fully $3 \mathrm{D}$, four equation mixture model with a correla tion for the interphase slip.

The FLICA4 full core coarse mesh VVER model used in the pre sent study and its validation are described in (Spasov and Kolev, 2013). The core model assumes one channel per fuel assembly and 30 axial nodes in the heated core. The fuel heat conduction model used 9 radial meshes in the fuel pellet, 1 for the gas gap and 1 for the cladding, and fitted nonlinear approximations of the fuel thermal properties from the specifications.

\subsection{Full core CTF model}

COBRA TF thermal hydraulic code with sub channel capabili ties was originally developed by the Pacific Northwest Laboratory in 1980 and since then has been modified by several institutions. COBRA TF also found use at the Pennsylvania State University (PSU) and subsequently at the North Carolina State University (NCSU) where it has been improved, updated, and subsequently re branded as CTF (Avramova et al., 2006; Avramova, 2007; Avramova and Cuervo, 2013). The CTF code uses a nine equation three field flow model (Avramova, 2007). The user can opt between 3D TH model and multi channel with cross flow.

The CTF coarse mesh core model for VVER used in this simula tion is described in (Jimenez and Sanchez, 2013). The TH model assumes one channel per fuel assembly and 30 axial nodes in the heated core. The fuel heat conduction model used 9 radial meshes in the fuel pellet, 1 for the gas gap and 1 in the cladding.

For the discussion and comparison of results, it is important to mention the modeling options that are common with the FLICA4 model and those that are code specific. The coarse mesh spatial discretization of the core is the same in both thermal hydraulic models. The fuel pin discretization in the heat conduction models is also unified and the gas gap conductance coefficient for burnt fuel is assumed to be a given constant. The CTF model differs from that of FLICA4 by the basic flow equations, the flow mixing model ing and the heat transfer models. For details see the references and the discussion of results in the sequel. There is also a small differ ence in the approximations of the fuel thermal properties as a function of temperature. In this simulation CTF used linear interpo lation in a table while the FLICA4 model used fitted non linear functional approximations based on the same table.

\subsection{Code couplings}

The DYN3D/CTF coupling at the nodal level is based on previous neutron kinetics thermal hydraulic coupling implementations within the NURESIM platform (Jimenez et al., 2015). Both codes have an Application Programing Interface (API) which was used 
to access the different methods in a modular way. Each code method is in charge of performing a specific task such as initializa tion, advancing a time step, checking for convergence or comput ing a steady state among others. In the practice, the API is used inside python scripts which master the coupled execution in steady state and transient mode. The data exchange between codes takes profit of the MED Coupling library provided in the Salome 6 platform. In this work, the coupling algorithm for steady states and transients was verified to work properly also in hexagonal geometries.

The COBAYA4/CTF coupling (García Herranz et al., 2017) is based on the use of each code API as described above and data exchange through the MED Coupling library in Salome 6. The Python script which governs the coupled calculation includes a damping scheme (Merino et al., 1993) to smooth the power profile and accelerate the convergence to achieve initial steady state in the performed transients. In this scheme the power at the current time step $(n)$ is expressed as $0.4^{*} P\left(t_{n-1}\right)+0.6 * P\left(t_{n}\right)$. A sensitivity study was carried out to establish the optimum damping value for this initial steady state. The geometrical coupling algorithm had to be adapted for hexagonal geometries. At the pin cell level, there is a COBAYA4/CTF coupling in Salome 6 for a hexagonal assembly (Cuervo et al., 2015). The results from this coupling (Kolev et al., 2016) will be subject of a future publication.

The COBAYA3/FLICA4 coarse mesh coupling (Jimenez, 2009) for hexagonal geometries is based on the coupling functions in Salome 5 and supplemented by FLICA4 routines. Regarding the time domain, an explicit marching scheme has been used between COBAYA3 FLICA4 which limits the time steps to achieve acceptable accuracy. The time step is set by the neutronics code and it needs to be small enough to fulfill the Courant limit in the TH solution.

\section{Cross-section libraries}

For the simulation of reactivity accidents, a multi parameter cross section library for transport corrected diffusion calculations with homogenized nodes was generated (Petrov et al., 2015) with the APOLLO2 code (Sanchez, 2010; Santandrea et al., 2008). The library is characterized by the following features:

- Two level $281 \mathrm{~g} / 42 \mathrm{~g}$ cross section calculation scheme with the Linear Surface Method of Characteristics (LS MOC) in APOLLO2

- JEFF3.1.1 nuclear data

- Table interpolation format

- Two energy groups

- Optimized parameter grid of 5 fuel Doppler temperature points $(470,852.5,1235,1617.5,2000 \mathrm{~K}), 3$ moderator temperature points $(470,545,620 \mathrm{~K})$ and 13 moderator density points (50, $76,102,128,154,207,259,311,363,467.5,572,676,885 \mathrm{~kg} /$ $\mathrm{m}^{3}$ ). The grid optimization (Sánchez Cervera et al., 2014) ensures uncertainty of $\mathrm{dk} \leq 120 \mathrm{pcm}$ in case of linear interpola tion in cross section tables

- Generated for a real reference core of Kozloduy 6 Cycle 8 with once, twice and three times burnt fuel assemblies

- 840 fuel compositions in $1 / 6$ core (28 assemblies $\times 30$ axial nodes) with given target exposure

- Uniform radial, top and bottom reflector compositions

- Explicit or implicit interface discontinuity factors for the fuel nodes

- No transport corrections for the reflector nodes

- A supplementary library of APOLLO2 calculated full core multi parameter pin by pin form functions is provided (Petrov et al., 2015), to be used for nodal calculations with pin power recon struction (PPR).
The cross section library is available in two formats:

- Compact: with scattering cross sections corrected for up scattering; with hexagon averaged interface discontinuity fac tors (IDF) implicitly included in the cross sections and node specific composition dependent kinetic parameters

- General multi group format (for MG solvers): with full matrix of scattering cross sections, explicit side dependent IDF and nodal kinetic parameters dependent on the composition and $\mathrm{TH}$ feedback.

The two library formats have been tested in steady state and transient nodal core simulations and shown to give results which are close to each other (Sanchez Cervera and Garcia Herranz, 2015; Kolev et al., 2016). The differences in the results are more pronounced in case of transients and steep flux gradients, see Sec tion 5.2. The library of pin by pin form functions for PPR has been tested beyond the scope of this paper in NURESAFE nodal/PPR cal culations with DYN3D for VVER mini cores (Hadek, 2015) vs. transport reference solutions.

The cross section library was validated in 2D COBAYA nodal dif fusion calculations vs. transport reference solutions at HZP (Ivanov, 2014) obtained with the TRIPOLI4 ${ }^{*}$ Monte Carlo code (Trama, 2011; Brun et al., 2015) and in 3D steady state core calculations at hot power vs. plant data.

Fig. 1 shows a comparison of COBAYA/FLICA4 computed assem bly powers in steady state at $91 \%$ hot power vs. plant data recorded by the Kozloduy 6 Core Monitoring System (CMS) for Cycle 8, 270.4 EFPD. The results show that the max absolute deviation in the computed assembly powers is within the $5 \%$ CMS uncertainty range. The computed $\mathrm{k}$ eff is 0.99491 which differs from 1 by $509 \mathrm{pcm}$. The main part of the deviations can be attributed to:

- Uncertainties in the given target burn ups for each node (core design code computed). The APOLLO2 predicted atomic number densities for these target burn ups inevitably differ from the actual ones

- Radial reflector modeling with one average reflector node, with out transport corrections

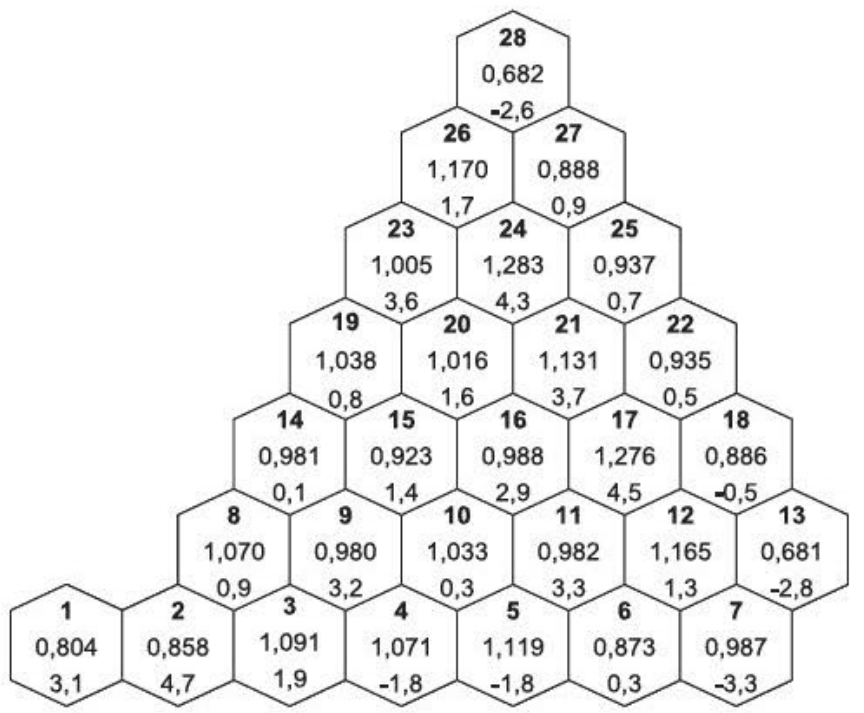

Fig. 1. COBAYA/FLICA4 computed assembly powers vs. Kozloduy-6 CMS plant data at $91 \%$ hot power. 1 - assembly no. in $1 / 6$ core numeration, 0.804 - computed relative assembly power, 3.1 - relative difference, \%. 
- The approximately estimated EOL gas gap heat conductance in the fuel heat conduction model

- Local errors in the CMS reconstructed assembly wise powers

\section{Test problems}

The MSLB test cases have been derived from the OECD VVER 1000 MSLB benchmark (Kolev et al., 2006). The reference core is Kozloduy 6 Cycle 8 at 270.4 EFPD. It contains once, twice and three times burnt fuel assemblies and is surrounded by a row of radial reflector assemblies and axial reflectors of the same width as the fuel assembly pitch.

The MSLB transient is initiated at HFP by a large break of steam line \#4 upstream of the steam intercept valve, outside the contain ment. Following the break and the scram signal, two of the most reactive peripheral control assemblies remain stuck out of the core, close to the location of maximum overcooling. Two MSLB scenarios have been specified. Scenario 1 is realistic, close to that used in the current licensing practice but not the same. It has an additional aggravating assumption of two stuck CR clusters instead of one. Scenario 2 is pessimistic, derived from Scenario 1 by assuming that the main coolant pump (MCP) of the faulted loop fails to trip on MSLB signal and all MCP remain in operation during the transient. The scram worth in Scenario 2 is assumed to be artificially reduced to less than $50 \%$ of the real one by adjusting the absorption cross sections in UOX CR assemblies and using this modified library. This allows for a significant return to power after scram in the 3D core N/TH calculations, which is a good test for the coupling schemes. For transient simulation Scenario 2 is considered only.

The test problems include:

- MSLB steady state calculations at HZP

- MSLB core boundary condition problem

For the discussion to follow, they are briefly summarized below.

\subsection{MSLB steady state problems at HZP}

HZP states are used to compare standalone code solutions. The considered states, listed in Table 1 allow all standard tests of nodal core physics codes in steady state. Detailed specifications are given in (Kolev et al., 2014). In Table 1, Scenario 1 means that the steady state calculation is to be performed with the realistic cross section library for UOX CR assemblies. In Scenario 2 the modified library with reduced absorption cross sections for controlled assemblies is to be used.

Table 1

Definition of the steady states.

\begin{tabular}{|c|c|c|c|}
\hline Number & $\mathrm{T}-\mathrm{H}$ conditions & Control rod positions & $\begin{array}{l}\text { Scenario } \\
\text { version }\end{array}$ \\
\hline 0 & HZP & Groups $1-10$ ARO* & 1 \\
\hline $1 \mathrm{a}$ & $\begin{array}{l}\text { HZP (near } \\
\text { critical) }\end{array}$ & $\begin{array}{l}\text { Groups } 1-5 \text { up, 6-81\% wd, 7-10 } \\
\text { down }\end{array}$ & 1 \\
\hline $1 b$ & $\mathrm{HZP}$ & Groups $1-10$ ARI & 1 \\
\hline 2 & HFP & $\begin{array}{l}\text { Groups } 1-9 \text { ARO } \\
\text { Group } 10 \text { is } 80 \% \text { wd }\end{array}$ & 2 \\
\hline 3 & HZP & $\begin{array}{l}\text { Groups } 1-10 \text { ARI } \\
\# 90 \text { is } 100 \% \text { wd }\end{array}$ & 1 \\
\hline 4 & HZP & $\begin{array}{l}\text { Groups } 1-10 \text { ARI } \\
\# 140100 \% \text { wd }\end{array}$ & 2 \\
\hline 5 & HZP & $\begin{array}{l}\text { Groups } 1-10 \text { ARI } \\
\# 140 \text { and } \# 117100 \% \text { wd }\end{array}$ & 2 \\
\hline
\end{tabular}

ARO - all rods out, ARI - all rods in.

\subsection{VVER MSLB core boundary condition problem}

The MSLB core N/TH problem was derived from the OECD VVER 1000 MSLB benchmark (Kolev et al., 2006) using pre calculated MSLB core boundary conditions and the corresponding event sequence. The core thermal hydraulic $\mathrm{BC}$ were computed in two options: using a CATHARE2 24 sector multi 1D vessel model with cross flow (Spasov et al., 2010) or a CFD simulation of the lower reactor vessel (Vyskocil, 2015). The validation of the CATHARE input model and the mapping scheme used to convert the coarse mesh data to 163 assembly inlet data are reported in (Spasov et al., 2010, 2013). The CATHARE2 computed MSLB core BC are specified in a NURESAFE report (Kolev et al., 2014) and shown here in Figs. 2 4. The CFD computed time dependent core inlet boundary conditions were obtained from a FLUENT calcula tion with realizable $\mathrm{k} \varepsilon$ turbulence model validated against the Kozloduy 6 vessel mixing experiment. They were used in para graph 5.3 to compare core MSLB simulation with CFD vs. CATHARE computed BC.

In the MSLB core boundary value problem the transient is initi ated through the pre calculated core thermal hydraulic BC. Scram is assumed to occur at $0.36 \mathrm{~s}$ of the MSLB transient. The time for full insertion of the control rods is $4 \mathrm{~s}$. Two peripheral control rods remain stuck out of the core after scram. In order to analyze the impact of vessel mixing models on the core transient, two different locations of the stuck rods were simulated one in fuel assemblies \#117 and \#140, well within the overcooled sector, and another in fuel assemblies \#63 and \#90 across the lateral boundary of the overcooled core sector.

\section{Results of the VVER MSLB simulation}

\subsection{Steady state calculations at HZP}

The recent versions of the 3D core physics codes were tested standalone on the hot zero power (HZP) calculations at the nodal level. The VVER 1000 HZP conditions correspond to Power $=3000 \mathrm{~W}$, Pin $=15.84 \mathrm{MPa}$, Pout $=15.7 \mathrm{MPa}$, Tin $=552.15 \mathrm{~K}$, Density, $\bmod =766.5 \mathrm{~kg} / \mathrm{m} 3$ and $\mathrm{Cb}=53 \mathrm{ppm}$.

Tables 2 and 3 show the computed $\mathrm{k}$ eff and core peaking fac tors in three of the considered HZP states, including such with big flux deformations. Note that the local differences are expressed as $100 *$ (DYN C4)/C4\%. More solutions and details can be found in (Kolev et al., 2016). It can be seen that the solutions of DYN3D 2G vs. COBAYA4 2G agree well. The DYN3D MG and COBAYA4 MG results for the power distributions obtained with the extended

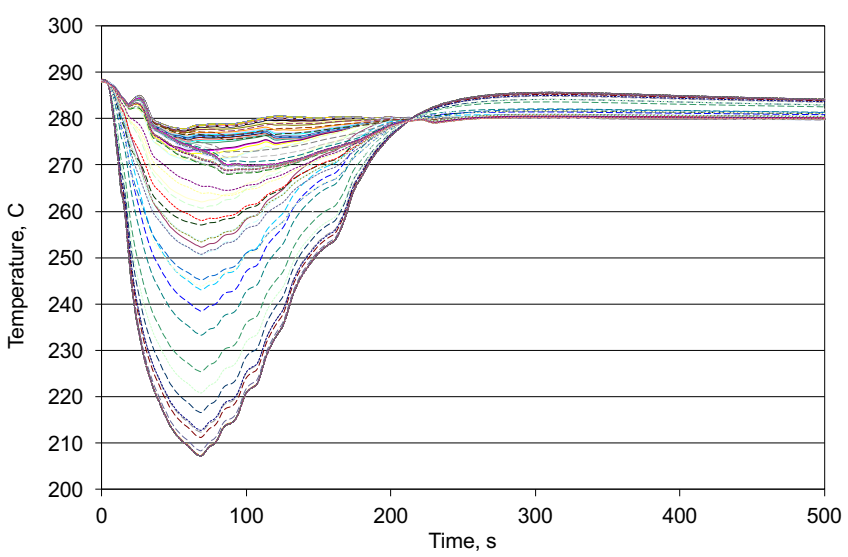

Fig. 2. CATHARE computed time history of the assembly-wise core inlet temperatures. 


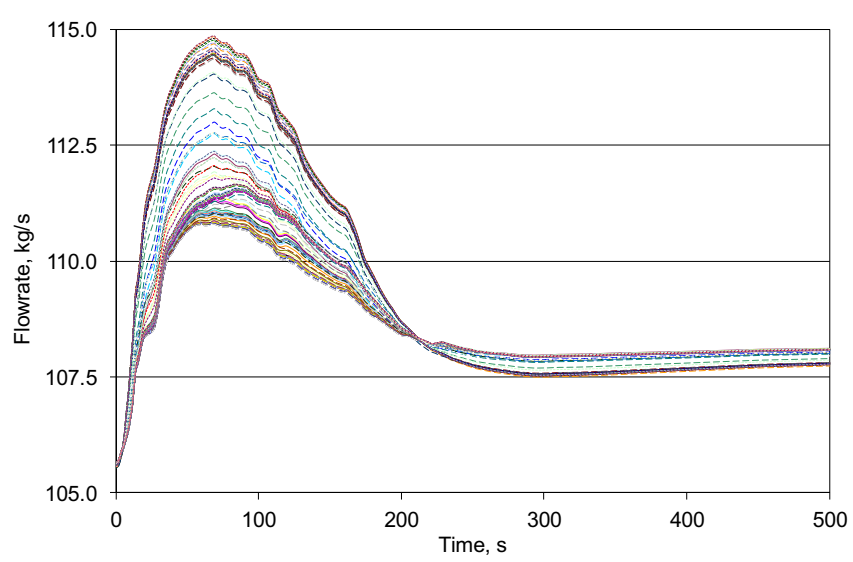

Fig. 3. CATHARE computed time history of the assembly-wise core inlet mass flow rates.

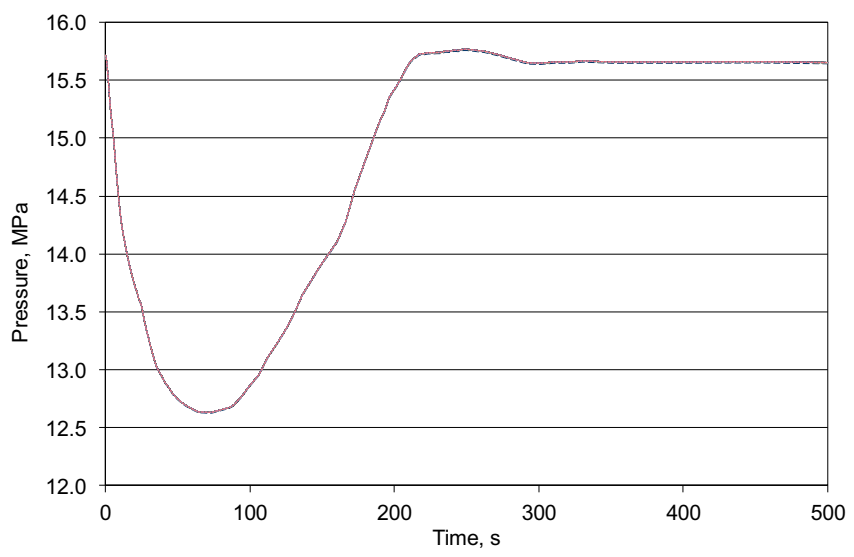

Fig. 4. CATHARE computed time history of the assembly-wise core outlet pressures. cross section library in MG format are closer to each other as com pared to those with the compact library. This is attributed to the rigorous MG models and unified solution algorithms in both codes.

Table 4 shows the COBAYA4 24N solutions used to test the spa tial convergence. The comparison of DYN3D and COBAYA4 6N solu tions vs. $24 \mathrm{~N}$ solutions shows that both flux solvers produce solutions which are well converged in space. The results are consis tent with those reported in (Kolev et al., 2011) for earlier code versions.

Figs. 58 show the DYN3D vs. COBAYA4 computed core axial and radial power distributions in State $1 \mathrm{a}$, respectively State 3 using the compact cross section library. In Fig. 6 coloured assem blies mark the location of the inserted control rods. In Fig. 8 the location of the stuck rod (\#90) and the inserted rods in State 3 are marked in colour. The code to code comparison shows gener ally good agreement, with a small radial tilt of systematic nature and somewhat larger differences in the assembly powers in regions of steep flux gradients. The max relative difference in the assembly powers is $2.7 \%$, in State 3 at the location of the stuck rod. The tilt and the discrepancies in local power are attributed mainly to the model differences and node sub division in COBAYA4 (see also Table 4).

\subsection{MSLB core transient results}

The location of the stuck rods was assumed to be in the periph eral assemblies \#117 and \#140, well within the overcooled core sector. Coupled code results obtained with COBAYA3/FLICA4, COBAYA4/CTF and DYN3D/CTF were compared code to code. For a meaningful comparison of the results, some modeling assump tions such as the spatial discretization in the neutron kinetics, ther mal hydraulics and the fuel heat conduction model, as well as the local loss coefficients in vertical direction were unified to the extent possible. In the core $\mathrm{TH}$ models there are differences in the basic flow equations, the flow mixing and heat transfer models, and the approximations of the fuel thermal properties (linear inter polation in tables in the CTF model vs. non linear fitted approxima tions used in the FLICA4 model) which can cause certain differences. The diversity of simulation results allows for the sepa

Table 2

DYN3D-2G vs. COBAYA-2G 6N results at HZP using the Compact library. Local differences in \%.

\begin{tabular}{|c|c|c|c|c|c|}
\hline Code & State & XS lib & Keff & Fxy & $\mathrm{Fz}$ \\
\hline DYN3D & 0 & Sc1 & 1.02509 & 1.343 & 2.960 \\
\hline COBAYA4 & 0 & Sc1 & 1.02534 & 1.341 & 2.983 \\
\hline$\Delta, \mathrm{pcm} ; \%$ & 0 & Sc1 & -25 & 0.1 & -1.0 \\
\hline DYN3D & $1 \mathrm{a}$ & Sc1 & 0.98758 & 1.390 & 1.938 \\
\hline COBAYA4 & $1 \mathrm{a}$ & Sc1 & 0.98804 & 1.406 & 2.001 \\
\hline$\Delta, \mathrm{pcm} ; \%$ & $1 \mathrm{a}$ & Sc1 & -46 & -1.0 & -1.5 \\
\hline DYN3D & 5 & Sc2 & 0.99866 & 2.452 & 2.787 \\
\hline COBAYA4 & 5 & Sc2 & 0.99891 & 2.504 & 2.801 \\
\hline$\Delta, \mathrm{pcm} ; \%$ & 5 & Sc2 & -25 & -0.9 & -0.5 \\
\hline
\end{tabular}

Table 3

DYN3D-MG vs. COBAYA-MG 6N results at HZP using the General MG format library. Local differences in \%.

\begin{tabular}{|c|c|c|c|c|c|}
\hline Code & State & XS lib & Keff & Fxy & $\mathrm{Fz}$ \\
\hline DYN3D & 0 & Sc1 & 1.02503 & 1.351 & 3.013 \\
\hline COBAYA4 & 0 & Sc1 & 1.02541 & 1.344 & 3.010 \\
\hline$\Delta, \mathrm{pcm} ; \%$ & 0 & Sc1 & -38 & 0.5 & 0.1 \\
\hline DYN3D & $1 \mathrm{a}$ & Sc1 & 0.98748 & 1.432 & 2.015 \\
\hline COBAYA4 & $1 \mathrm{a}$ & Sc1 & 0.98757 & 1.431 & 1.997 \\
\hline$\Delta, \mathrm{pcm} ; \%$ & $1 \mathrm{a}$ & Sc1 & -9 & -0.1 & 0.9 \\
\hline DYN3D & 5 & $\mathrm{Sc} 2$ & 0.99886 & 2.431 & 2.853 \\
\hline COBAYA4 & 5 & $\mathrm{Sc} 2$ & 0.99923 & 2.446 & 2.853 \\
\hline$\Delta, \mathrm{pcm} ; \%$ & 5 & $\mathrm{Sc} 2$ & -37 & -0.6 & 0 \\
\hline
\end{tabular}


Table 4

DYN3D vs. COBAYA4 $6 \mathrm{~N}$ vs. COBAYA4 $24 \mathrm{~N}$ results at HZP using the Compact library.

\begin{tabular}{|c|c|c|c|c|c|}
\hline Code & State & XS lib & Keff & Fxy & $\mathrm{Fz}$ \\
\hline DYN3D & 0 & Sc1 & 1.02509 & 1.343 & 2.960 \\
\hline COBAYA $6 \mathrm{~N}$ & 0 & Sc1 & 1.02534 & 1.341 & 2.983 \\
\hline COBAYA $24 \mathrm{~N}$ & 0 & Sc1 & 1.02529 & 1.342 & 2.985 \\
\hline DYN3D & $1 \mathrm{a}$ & Sc1 & 0.98758 & 1.390 & 1.938 \\
\hline COBAYA $6 \mathrm{~N}$ & $1 \mathrm{a}$ & Sc1 & 0.98804 & 1.406 & 2.001 \\
\hline COBAYA $24 \mathrm{~N}$ & $1 a$ & Sc1 & 0.98794 & 1.438 & 2.004 \\
\hline DYN3D & 5 & Sc2 & 0.99866 & 2.452 & 2.787 \\
\hline COBAYA $6 \mathrm{~N}$ & 5 & $\operatorname{Sc} 2$ & 0.99891 & 2.504 & 2.801 \\
\hline COBAYA $24 \mathrm{~N}$ & 5 & $\operatorname{Sc} 2$ & 0.99886 & 2.491 & 2.807 \\
\hline
\end{tabular}

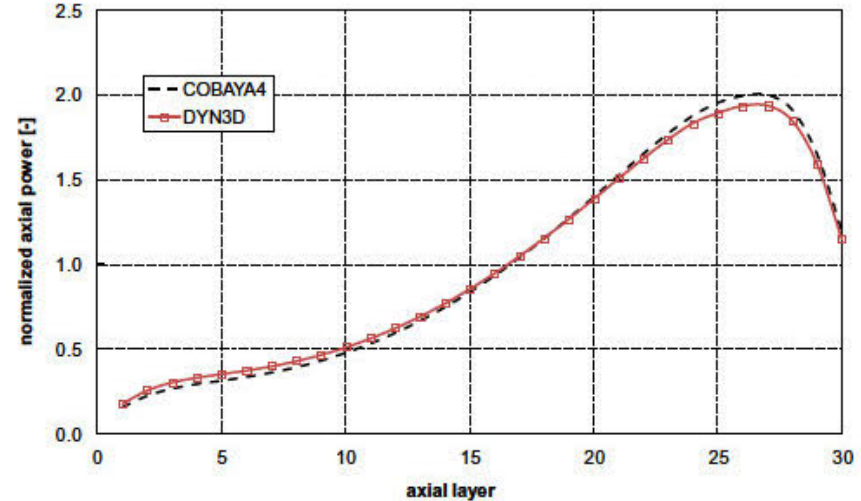

Fig. 5. HZP state 1a: DYN3D-2G vs. COBAYA-2G $6 \mathrm{~N}$ computed radially averaged core power $(\mathrm{dk}=-46 \mathrm{pcm})$.

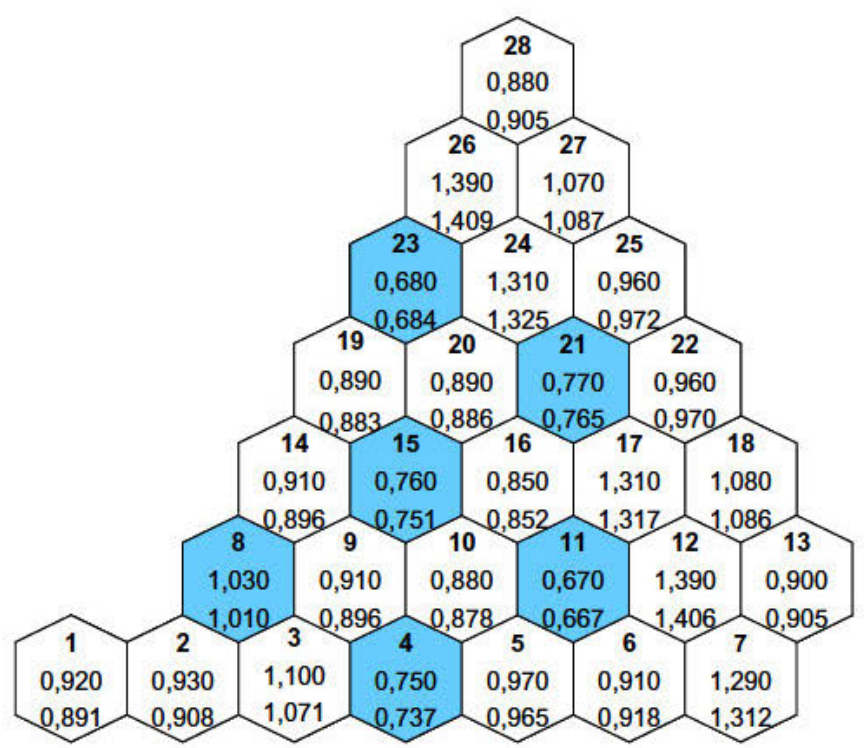

Fig. 6. HZP state 1a: DYN3D-2G vs. COBAYA-2G 6N computed axially averaged assembly powers. 1 - assembly no. in $1 / 6$ core numeration, 0.920 - DYN3D relative assembly power, 0.891 - COBAYA4 relative assembly power.

ration of the effects of core physics and thermal hydraulics model ing assumptions.

In order to study the impact of vessel mixing modeling on the MSLB core dynamics, separate core simulations with CATHARE and CFD computed MSLB core BC have been performed. This sec tion presents the results obtained with core BC from a CATHARE2 24 sector RPV calculation. Core simulation results with CFD com puted MSLB core BC will be discussed in Section 5.3. Note that all results throughout this paper are obtained using the compact cross section library, unless explicitly stated otherwise.

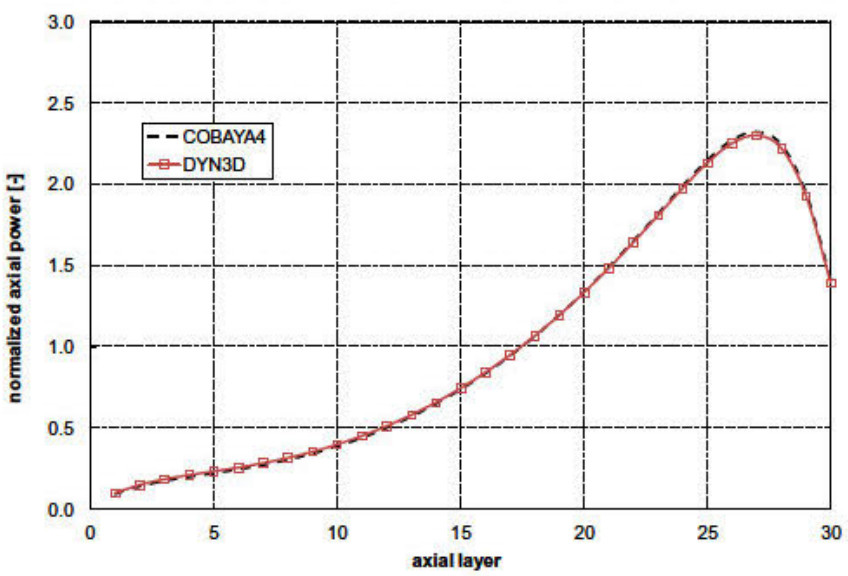

Fig. 7. HZP state 3: DYN3D-2G vs. COBAYA-2G $6 \mathrm{~N}$ computed radially averaged core power $(\mathrm{dk}=-83 \mathrm{pcm})$.

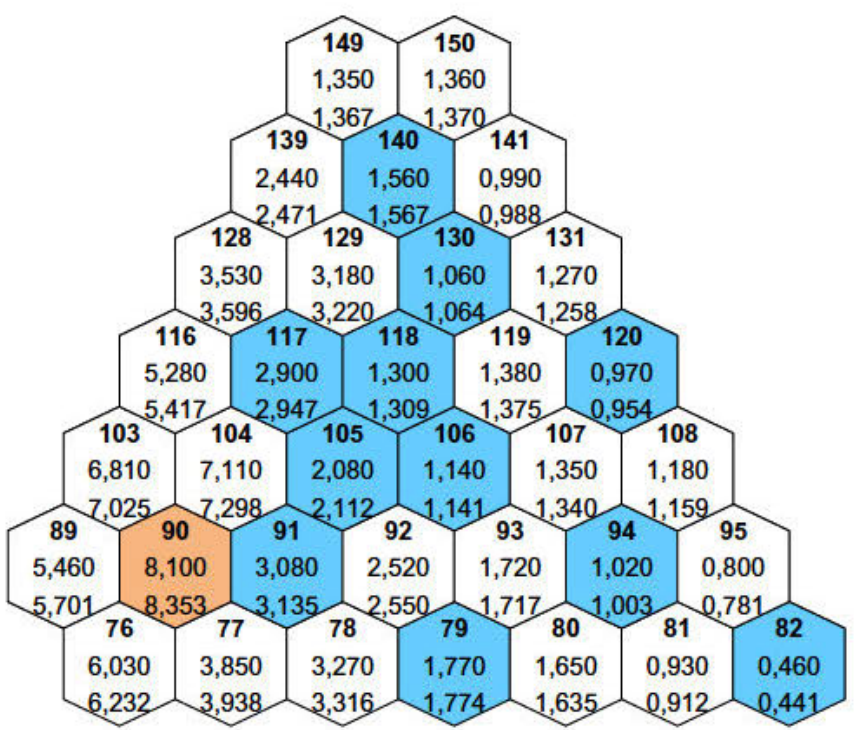

Fig. 8. HZP state 3: DYN3D-2G vs. COBAYA-2G $6 \mathrm{~N}$ computed axially averaged assembly powers. 76 - assembly no. in full-core numeration, 6.030-DYN3D relative assembly power, 6.232 - COBAYA4 relative assembly power.

Fig. 9 shows the predicted time history of total core power. A significant return to power can be seen, with a maximum of 66 $68 \%$ of the nominal rated power. Table 5 summarizes the results for the total power and nodal core peaking factors at time of max imum return to power as computed by the considered codes. Table 6 illustrates the time history of the core reactivity as com puted by the 3D models. In Tables 5 and 6 superscript 1 denotes solutions with the compact cross section library and superscript 


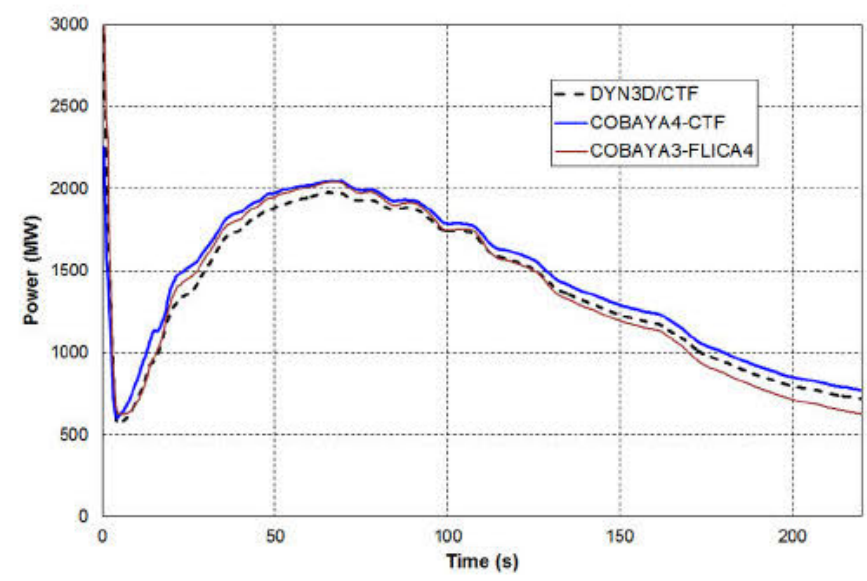

Fig. 9. Time history of the total core power with stuck rods in \#117 and \#140.

2 denotes solutions with the general MG format library. DYN3D/ CTF and COBAYA3/FLICA4 predict a slight return to criticality of a few pcm while the core reactivity in the COBAYA4/CTF solution is close to criticality but remains slightly negative. The behavior of the core is determined by the dynamics of a small number of assemblies in the overcooled sector around the stuck rod locations, and the core power is released mainly in these assemblies. Hot assembly is \#129, located between the assemblies \#117 and \#140 with the stuck rods.

The results in Fig. 9 and Table 5 show a good overall agreement. The COBAYA4/CTF and DYN3D/CTF computed total power curves are nearly parallel with a shift which indicates somewhat different tripped rod worth. This difference is attributed mainly to the neu tron kinetics models. On the other hand, the comparison of COBAYA3/FLICA4 vs. COBAYA4/CTF results shows the impact of fuel heat conduction and core mixing modeling. It should be noted that the core physics models in COBAYA3 and COBAYA4 are essen tially the same. Fig. 9 shows that the results with these couplings are close to each other until app. $130 \mathrm{~s}$ of the transient, and after that some decline of the COBAYA3/FLICA4 solution from that of COBAYA4/CTF can be seen. The analysis, involving simulation with an independent coupling of COBAYA 3 shows that this is mainly due to the use of different approximations of the fuel thermal properties: CTF uses linear interpolation in tables while FLICA4 employs nonlinear fitted approximations based on the same tables.

Fig. 10 illustrates a comparison of the radial core power distri butions at time of max return to power ( $69 \mathrm{~s}$ ) as computed by COBAYA4/CTF using the cross section library in compact vs. gen eral MG format (see the discussion of the impact of this refinement at the end of paragraph 5.2).

The hot assembly parameters at time of max overcooling $(69 \mathrm{~s}$ of the transient) are shown in Figs. 11 13, as computed at the nodal level. The results show that despite the high amount of energy release in the hot assembly, no bulk boiling occurs except for a little sub cooled boiling at the walls predicted by FLICA4. This is mainly due to the deep overcooling and low inlet temperature. The values of the hot assembly safety parameters, such as fuel cen ter temperature and cladding temperature remain within the acceptable limits for burnt fuel.

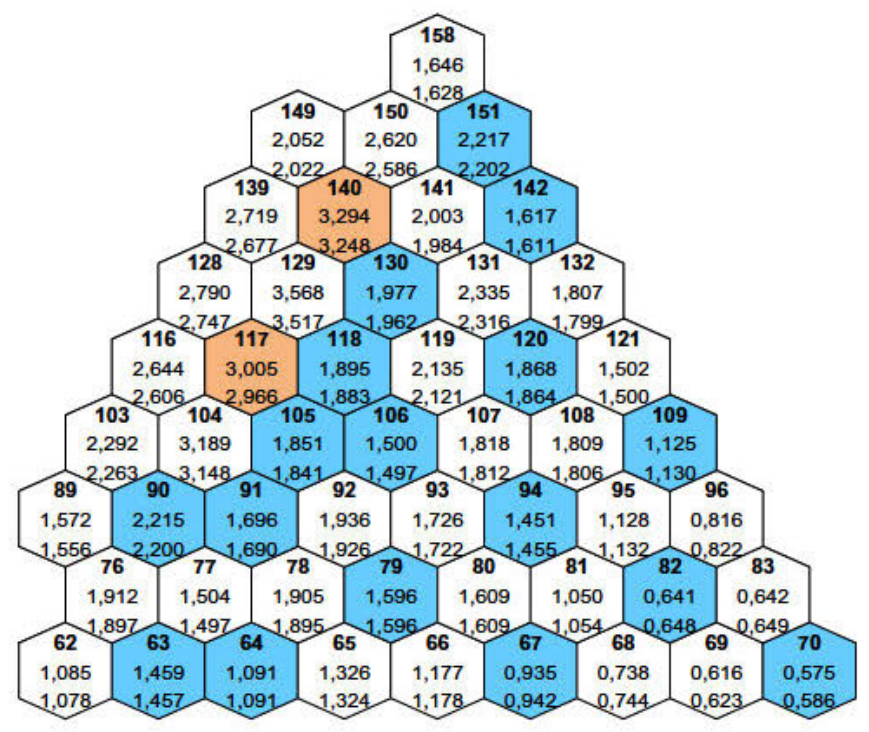

Fig. 10. COBAYA4/CTF computed radial power distribution at $69 \mathrm{~s}$ using compact vs. general format XS library. 62 - assembly no. in full-core numeration, 1.085 relative power with the compact XS lib, 1.078 - relative power with the general format XS lib.

Table 5

Total power and peaking factors at time of max return to power. Stuck rods in assemblies \#117 and \#140.

\begin{tabular}{|c|c|c|c|c|c|c|}
\hline Core BC by & Codes & Time, s & P tot, MW & Fxy & $\mathrm{Fz}$ & $\mathrm{Fq}$ \\
\hline Cathare2 & DYN3D/CTF & 68 & 1979 & 3.132 & 1.404 & 4.32 \\
\hline Cathare2 & Cobaya $4 / \mathrm{CTF}^{1}$ & 69 & 2047 & 3.568 & 1.572 & 4.26 \\
\hline Cathare2 & Cobaya4/CTF ${ }^{2}$ & 69 & 2098 & 3.517 & 1.586 & 4.22 \\
\hline Cathare2 & Cobaya3/FUCA4 & 68 & 2043 & 3.712 & 1.599 & \\
\hline
\end{tabular}

${ }^{1}$ Compact XS lib.

2 General format XS lib.

Table 6

Reactivity computed by the 3D models. Stuck rods in assemblies \#117 and \#140.

\begin{tabular}{|c|c|c|c|c|}
\hline \multirow[t]{2}{*}{ Codes } & \multicolumn{4}{|c|}{ Reactivity, \$/Time } \\
\hline & $0 \mathrm{~s}$ & $4.4 \mathrm{~s}$ & $69 s$ & $200 s$ \\
\hline DYN3D/CTF & -0.002 & -3.197 & 0.004 & -0.126 \\
\hline Cobaya $4 / \mathrm{CTF}^{1}$ & -0.005 & -3.334 & -0.040 & -0.176 \\
\hline Cobaya $4 / \mathrm{CTF}^{2}$ & -0.005 & -2.883 & -0.034 & -0.175 \\
\hline Cobaya3/FUCA4 & 0.000 & -3.774 & 0.001 & -0.164 \\
\hline
\end{tabular}

\footnotetext{
1 Compact XS lib.

2 General format XS lib.
} 


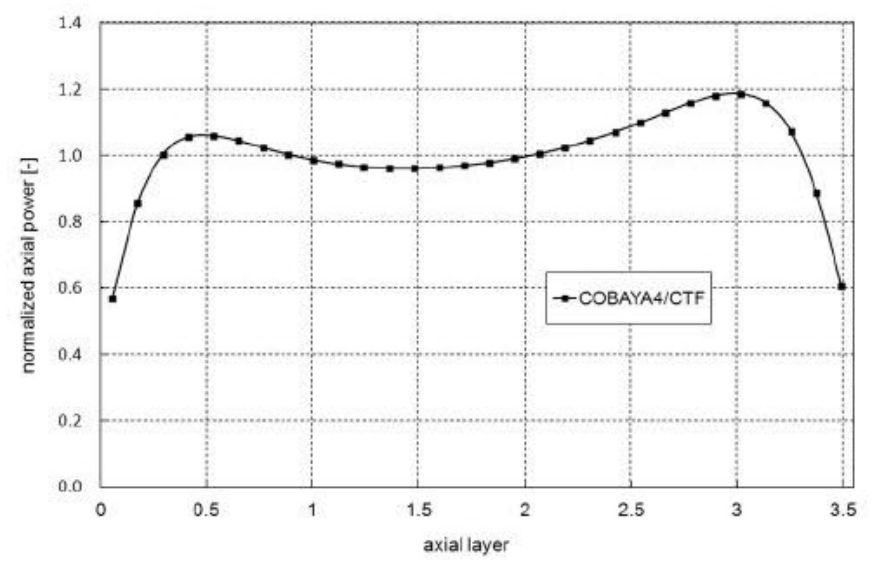

Fig. 11. Hot assembly (\#129) axial power distribution at time of max power (69 s).

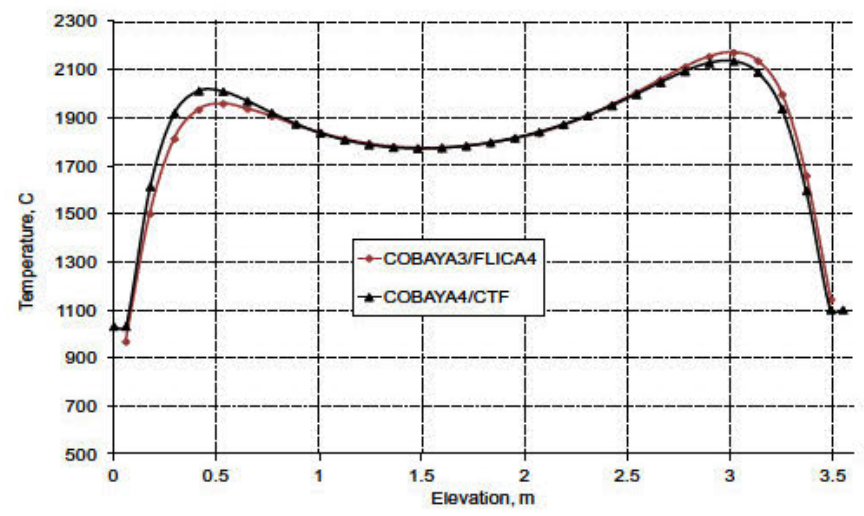

Fig. 12. Hot assembly axial distribution of the fuel center temperature (node averaged for radial mesh 1) at $69 \mathrm{~s}$.

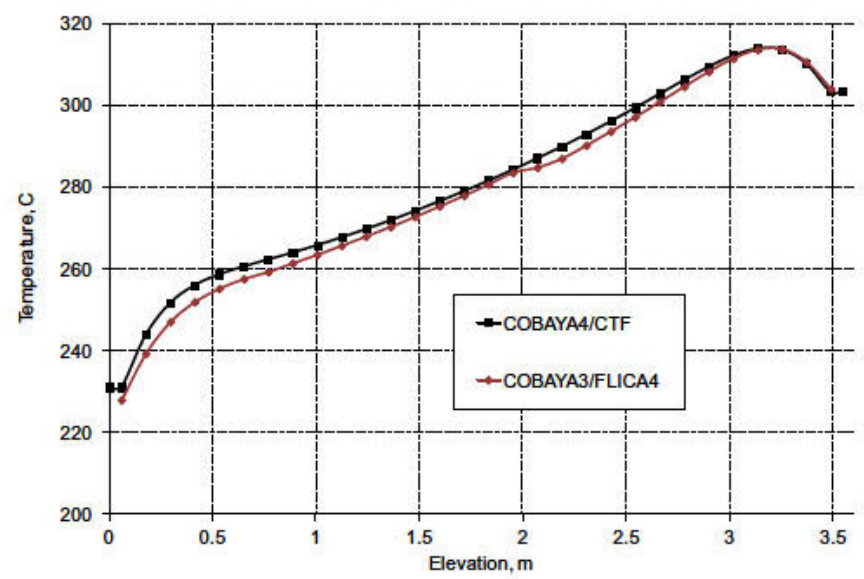

Fig. 13. Hot assembly axial profile of the fuel cladding surface temperature at $69 \mathrm{~s}$.

It is worth noting that a sub channel CTF thermal hydraulic model of a VVER assembly was developed in the frame of NURE SAFE (Spasov et al., 2014) and tested on a hot assembly TH bound ary condition problem in comparison with a FLICA4 sub channel model. The results of this analysis (Kolev et al., 2016) will be pre sented in a future publication.

In order to assess the spatial convergence of the nodal solutions and the effects of model refinements, numerical experiments were carried out as summarized below.

Table 7 illustrates the impact of the neutronic mesh refinement. Transient solutions with node sub division to 6 and 24 triangles per hexagon $(6 \mathrm{~N}, 24 \mathrm{~N})$ in COBAYA were compared using the same convergence criteria. In the $24 \mathrm{~N}$ solution the maximum return to power is lower by $29 \mathrm{MW}$ (which is app. $1 \%$ of the nominal rated power) and the hexagonal node peaking factors are only slightly different. The COBAYA $6 \mathrm{~N}$ transient solution is well converged in space.

The coupled COBAYA/CTF core model has the potential for fur ther improvements through the use of simultaneous COBAYA $6 \mathrm{~N}$ and thermal hydraulic node sub division to 6 channels (6C) per hexagon. This requires some verification runs using the corre sponding functions in the CTF code API for hexagonal/triangular geometry. A preliminary test of the TH mesh sub division was car ried out in MSLB simulation (Kolev et al., 2016) with an indepen dent coupling of COBAYA3 $6 \mathrm{~N} / \mathrm{COBRA3c} 6 \mathrm{C}$. The effect was app. $1 \%$ higher maximum total power and $1.8 \%$ lower Fxy peaking factor due to the refined mesh of the feedback action.

Numerical experiments (not illustrated here) show that a refinement of the radial CTF fuel model mesh from 7 to 10 equidis tant radial points in the pellet gives $1 \mathrm{MW}$ higher total power and practically the same volumetric peaking factor. The heat conduc tion solution is well converged in space.

The impact of different core mixing models in CTF was studied in comparative calculations with given turbulent mixing coeffi cient Beta $=$ Transfer mass flux $/$ Axial mass flux $=0.001$ vs. single phase mixing coefficient according to Rogers Rosehart (Avramova, 2007). The results at time of maximal return to power (69 s) are practically the same: Ptot $=2047.13 \mathrm{MW}, \mathrm{Fq}=4.265$ when using Rogers Rosehart mixing model while Ptot $=2046.86 \mathrm{MW}, \mathrm{Fq}=4.263$ with mixing coefficient equal to 0.001 . The Rogers Rosehart model was adopted as basic in this study.

Comparative simulations with COBAYA4/CTF using the compact vs. the general MG format cross section library show that in the considered MSLB transient the effect of using the full matrix of scattering cross sections and explicit IDF, as well as thermo hydraulic feedback dependent kinetic parameters is relatively small but not negligible (see Fig. 10 and Tables 5, 6). The max total power at $69 \mathrm{~s}$ is $2098 \mathrm{MW}$ (gen. format lib) vs. $2047 \mathrm{MW}$ (compact lib), while the volumetric peaking factor is lower by app. $1 \%$ due to the different 3D flux redistribution.

DYN3D nodal/PPR calculations have been tested for mini cores in the NURESAFE project beyond the scope of this article (Hádek, 2016; Kolev et al., 2016). The full core nodal cross section library for MSLB analysis (Petrov et al., 2015) has a provision for PPR with a supplementary library of APOLLO2 computed pin by pin nodal power shapes (form functions). The full core nodal model of DYN3D is ready to use with PPR for the hot assembly (available model, cross section library and full core multi parameter pin by pin form function library for PPR).

\subsection{MSLB core simulation with CFD computed boundary conditions}

For improved resolution of the MSLB core vessel simulation, the use of CFD computed core BC was explored. The objective was to analyze the advantages and limitations of such refinements for the simulation of reactivity transients with sector formation. A computationally efficient FLUENT model of the down comer and the lower plenum with realizable $\mathrm{k} \varepsilon$ ( $\mathrm{rk} \varepsilon$ ) turbulence model was created and tested (Vyskočil, 2013) against the Kozloduy 6 vessel mixing experiment (Kolev et al., 2007). Time dependent MSLB core boundary conditions were calculated with this model by solving the MSLB RPV boundary condition problem of the OECD VVER 1000 MSLB benchmark (Kolev et al., 2006). In this calculation an unstructured spatial mesh of 1.5 million cells and second order upwind advection scheme were used. 
Table 7

COBAYA4 6N/CTF vs. COBAYA4 24N/CTF transient solution at 69 s. Stuck rods in assemblies \#117, \#140.

\begin{tabular}{|c|c|c|c|c|c|c|}
\hline Core BC by & Comp. model & Time, s & P tot, MW & Fxy & $\mathrm{Fz}$ & $\mathrm{Fq}$ \\
\hline Cathare2 & Cobaya4/CTF $6 \mathrm{~N}$ & 69 & 2047 & 3.562 & 1.572 & 4.26 \\
\hline Cathare2 & Cobaya4/CTF $24 \mathrm{~N}$ & 69 & 2018 & 3.556 & 1.586 & 4.29 \\
\hline
\end{tabular}

280.70

276.55

272.40

268.25

264.10

259.95

255.80

251.65

247.50

243.35

239.20

235.05

230.90

226.75

222.60

218.45

214.30

210.15

206.00

Fig. 14. Map of the FLUENT rk $\varepsilon$ computed assembly inlet temperatures (C) at $70 \mathrm{~s}$.

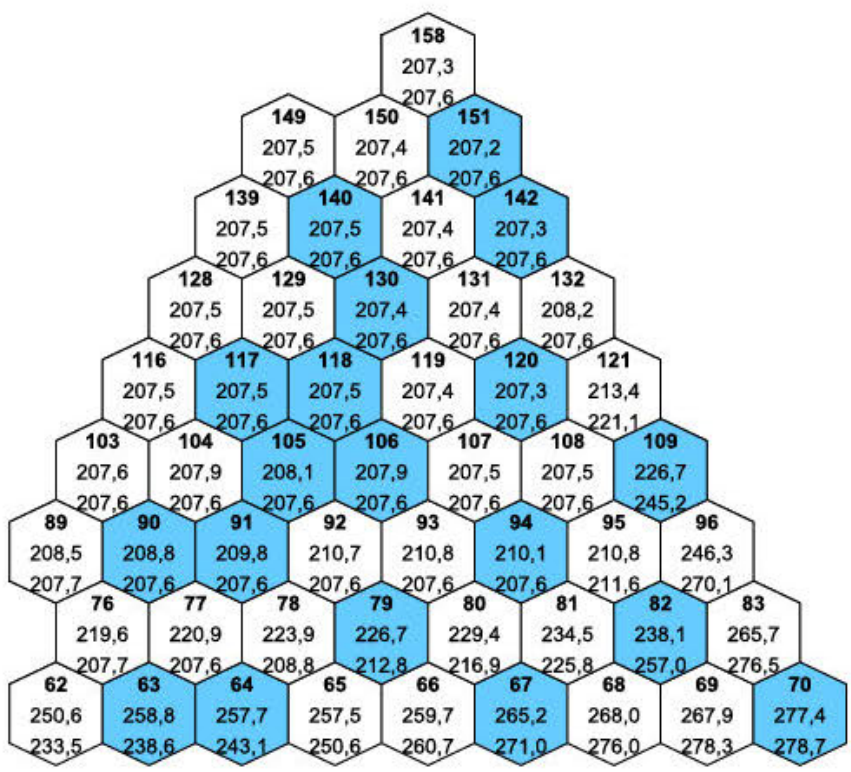

Fig. 15. FLUENT rke vs. CATHARE2 computed core inlet temperatures (C) at 70 s. 62 - assembly no. in full-core numeration, 250.6 - FUENT rk $\varepsilon$ computed Tin (C), 233.5 - CATHARE2 computed Tin (C).

This section summarizes the comparison of core simulation results obtained using CFD vs. CATHARE computed core BC. Figs. 14 and 15 illustrate the predicted disturbed sector formation by snap

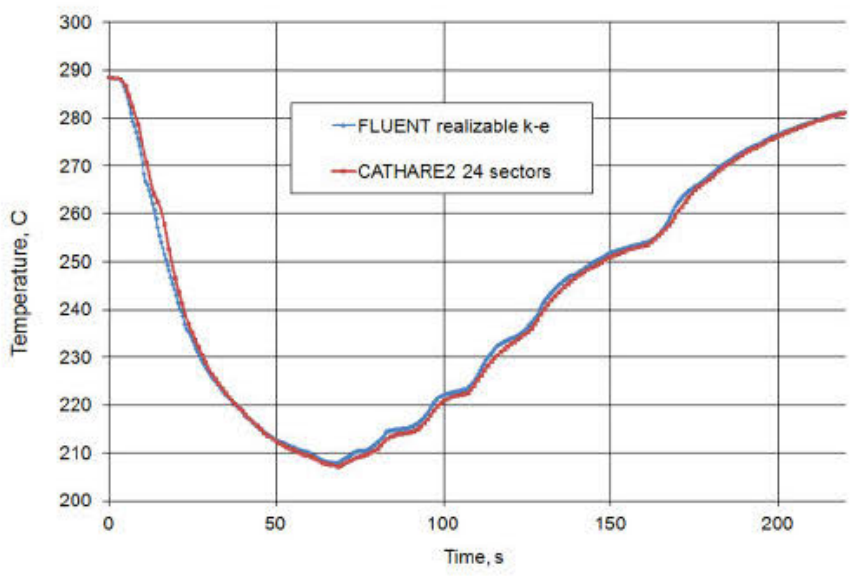

Fig. 16. Time history of assembly \#90 inlet temperature.

shot maps of the assembly inlet coolant temperatures at $70 \mathrm{~s}$ from the onset of the MSLB transient. This is near the time of max over cooling (69 s). Figs. 1517 show that in this particular comparison the CFD (Vyskocil, 2015) and CATHARE 24 sector (Spasov et al., 2010) computed BCs are close to each other in the interior of the disturbed sector and may be substantially different around the lat eral boundary of the disturbed sector, because of differences in the predicted loop flow rotation and mixing. We explore the impact of the use of CFD computed BCs on the local and global core dynamics when the stuck rod perturbations are imposed well within the dis turbed sector, and at the lateral sector boundaries. 


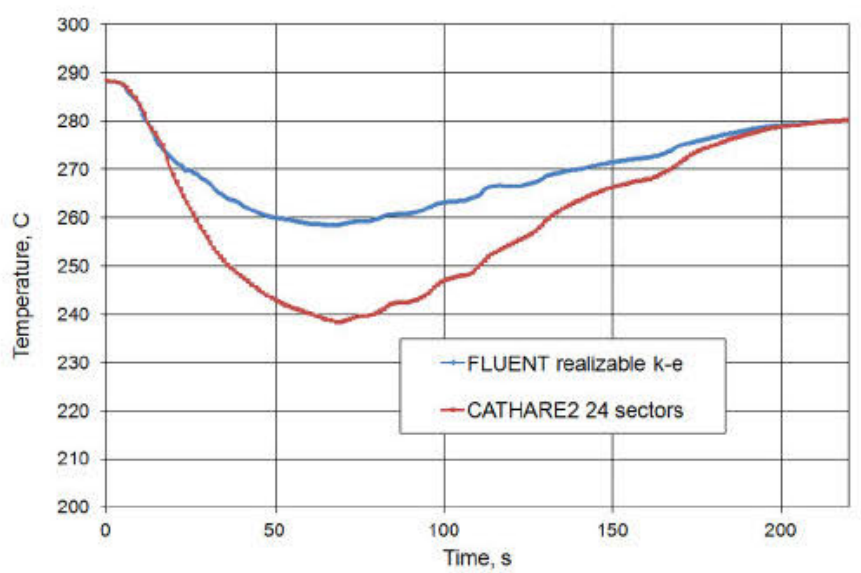

Fig. 17. Time history of assembly \#63 inlet temperature.

The results with the stuck rods in the interior of this sector (\#117, \#140) show that the corresponding total core powers and peaking factors are close to each other, see Table 8 . The effect of using CFD computed core BC is small and mainly at the periphery of the disturbed sector. The maximum total power is lower by 19 MW due to the CFD predicted stronger mixing at the lateral sec tor boundaries.

However, this may not be the case when the stuck rods are located around the lateral boundary of the disturbed sector. In order to explore this possibility, the location of the two stuck rods was assumed to be in fuel assemblies \#63 and \#90 at the lateral boundary of the overcooled core sector (see Fig. 19). These control rods are from the same rod groups and at the same radial positions as in the preceding case. Figs. 16 and 17 show that in this case the FLUENT rk $\varepsilon$ and CATHARE computed time dependent inlet BC for assembly \#63 are different because of the higher CFD resolution around the lateral boundaries of the disturbed sector. In this case the impact of the CFD computed BC on the core dynamics is a little more pronounced in terms of local parameters. See Fig. 18 for the corresponding differences in the total core power, and Fig. 19 for the radial power distributions at $70 \mathrm{~s}$ (app. the time of maximum return to power). The total power and the peaking factors are sum marized in Table 9. FLUENT rke predicts more coolant mixing around the stuck rods and the maximum return to power with CFD BC is lower by $40 \mathrm{MW}$. The peaking factors obtained with CATHARE computed BC are only slightly different (see Table 9) since the hot assembly \#104 is located well within the overcooled sector.

The results show that the main differences in the CFD vs. CATH ARE computed assembly inlet temperatures (and correspondingly in the local assembly powers) are around the lateral boundaries of the disturbed sector due to the higher CFD resolution. This suggests that the CFD computed core BC may be important in the analysis of hypothetical scenarios of asymmetric VVER coolant transients with multiple rod perturbations of the core.

In conclusion, we have presented a sample comparison of MSLB results using core BC computed with two particular models: CATH

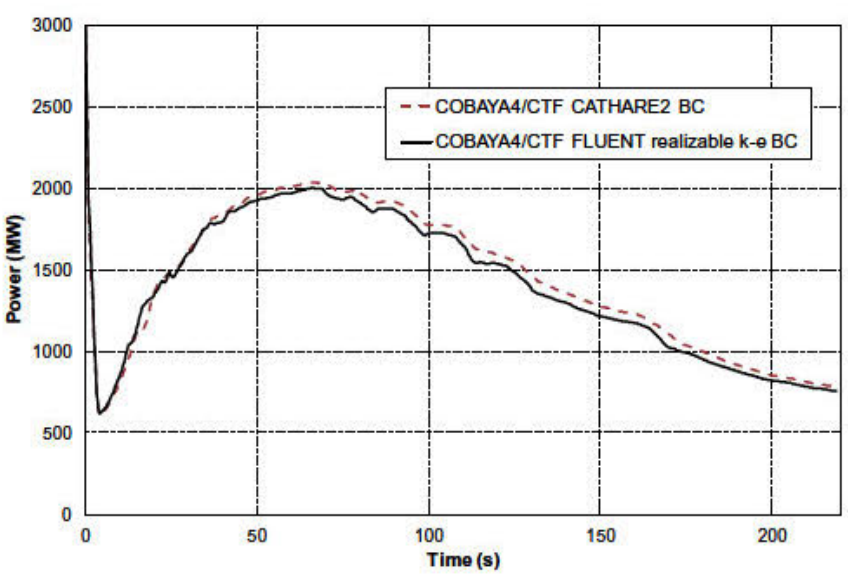

Fig. 18. Time history of total power with stuck rods in \#63 and \#90 FLUENT rke core BC vs. CATHARE2 core BC.

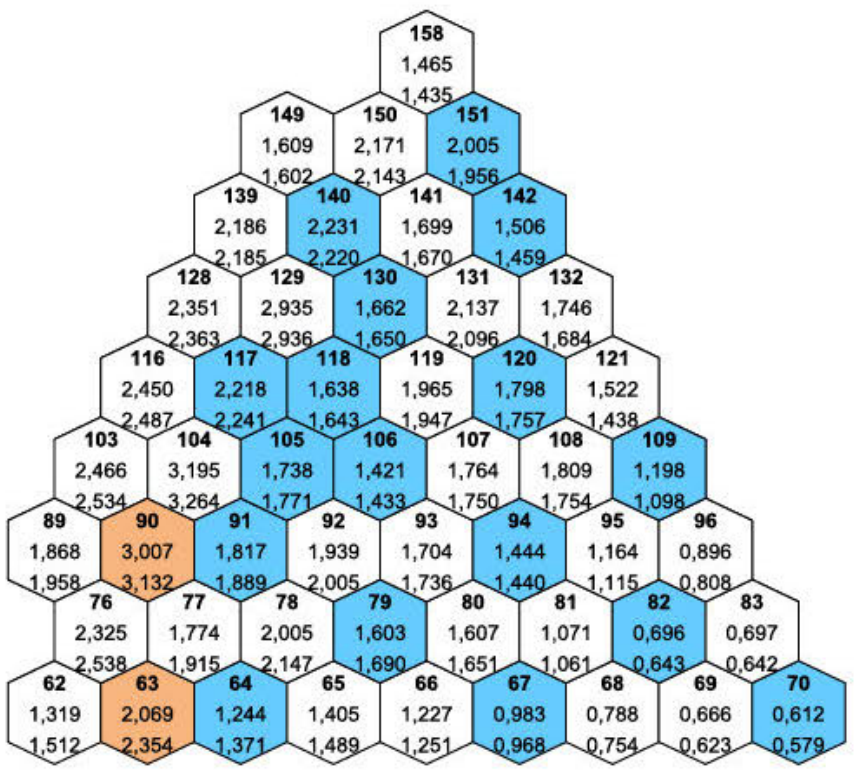

Fig. 19. COBAYA4/CTF computed assembly powers at $70 \mathrm{~s}$ with stuck rods in \#63 and \#90. 62 - assembly no. in full-core numeration, 1.319 - relative power with FLUENT rke computed BC, 1.512 - relative power with CATHARE2 computed BC.

ARE 24 sector coarse mesh and FLUENT with a limited number of cells and rke turbulence model. Based on the comparison of CFD solutions in the OECD VVER 1000 vessel mixing benchmark report (Kolev et al., 2010) and in related publications such as (Bieder et al., 2007; Hoehne, 2009) (Böttcher and Krüßmann, 2010) one can expect some scatter in the parameters of the core transient when using transient core boundary conditions obtained with different computationally efficient CFD models. Additional testing is neces sary for accuracy cost optimization.

Table 8

Total power and peaking factors at time of max return to power. Stuck rods in assemblies \#117 and \#140, hot assembly is \#129.

\begin{tabular}{|c|c|c|c|c|c|}
\hline Core BC computed by & Core $\mathrm{N} / \mathrm{TH}$ codes & P tot, MW & Fxy & $\mathrm{Fz}$ & Fq \\
\hline Cathare2 & Cobaya4/CTF & 2047 & 3.562 & 1.572 & 4.260 \\
\hline Fluent $r k \varepsilon$ & Cobaya4/CTF & 2028 & 3.581 & 1.604 & 4.313 \\
\hline
\end{tabular}


Table 9

Total power and peaking factors at time of max return to power. Stuck rods in assemblies \#63 and \#90, hot assembly is \#104.

\begin{tabular}{|c|c|c|c|c|c|}
\hline Core BC computed by & Core N/TH codes & P tot, MW & Fxy & $\mathrm{Fz}$ & $\mathrm{Fq}$ \\
\hline Cathare2 & Cobaya4/CTF & 2036.5 & 3.264 & 1.590 & 4.020 \\
\hline Fluent rke & Cobaya4/CTF & 1996.9 & 3.195 & 1.634 & 4.067 \\
\hline
\end{tabular}

\section{Summary and conclusions}

Recent developments in the NURESIM platform nodal calcula tion schemes for core analysis were implemented and tested in VVER MSLB core simulation.

The testing of the core physics models shows that the neutron flux solutions are well converged in space. Node subdivision to 24 triangles per hexagon in COBAYA4 does not substantially improve the results.

The hexagonal geometry versions of COBAYA4 and DYN3D at the nodal level and their couplings with full core CTF and FLICA4 thermal hydraulic models reach maturity for industrial applications.

The DYN3D code is capable of nodal/PPR calculations for VVER RIA analysis, which have been tested for mini cores in the NURE SAFE project beyond the scope of this paper. It is ready to use for VVER mini cores and full core simulation with PPR for the hot assembly.

The coupled COBAYA4/CTF models for VVER applications have the potential for further improvement through the use of thermal hydraulic node sub division to six triangles per hexagon. This requires the activation and verification of the corresponding functions in the CTF code API for hexagonal/triangular geometry.

The results with coarse mesh and CFD computed core boundary conditions show that the validated system code models of the RPV are applicable to MSLB analysis but have some limitations in reso lution for the local effects.

Validated CFD calculations of the down comer and the lower plenum conditions are found to improve the resolution in the 3D core simulation of asymmetric coolant transients with sector for mation. In the considered cases the impact of this refinement is mild and is more pronounced around the periphery of the dis turbed sector. It may be stronger in hypothetic scenarios of asym metric VVER coolant transients with multiple rod perturbations of the core.

We have presented a sample comparison of MSLB results mak ing use of transient core boundary conditions computed with two particular models: CATHARE 24 sector coarse mesh and FLUENT with a limited number of cells and rke turbulence model. Based on the lessons from the OECD VVER 1000 vessel mixing bench mark and the studies in related publications one can expect some scatter in the parameters of the core transient when using different computationally efficient CFD models. Additional testing is neces sary for accuracy cost optimization.

\section{Acknowledgements}

This work was partially funded by the EC in the frame of the NURESAFE EU project, contract no. 323263 and by the Ministry of science and education in Bulgaria under contract D01 191 2014. Part of the results in this work has been obtained with the use of CATHARE2, developed by CEA, EDF, AREVA NP and IRSN. The authors gratefully acknowledge the collaboration of Yann Perin from GRS with the development of the CTF coupling interface in Salome.

\section{References}

Ahnert, C., Capacities and achievements of the COBAYA4 code after the NURESAFE project, NURESAFE Open General Seminar, Brussels, November 4-5, 2015.

ANSYS-Fluent site: http://www.ansys.com/Products/Fluids/ANSYS-Fluent.

Aragones, J.M., Ahnert, C., Garcia-Herranz, N., 2007. The analytic coarse-mesh finite difference method for multigroup and multidimensional diffusion calculations. Nucl. Sci. Eng. 157, 1-15.

Avramova, M., 2007. CTF Theory Manual. Pennsylvania State University.

Avramova, M., D. Cuervo, K. Ivanov, et al., Improvements and applications of COBRA-TF for stand-alone and coupled LWR safety analyses. In: Proceedings of the American Nuclear Society's Topical Meeting on Reactor Physics (PHYSOR '06), Vancouver, Canada, September 2006.

Avramova, M., Cuervo, D., 2013. Assessment of CTF boiling transition and critical heat flux modeling capabilities using the OECD/NRC BFBT and PSBT benchmark databases. Sc. Technol. Nucl. Installations 2013, (2013), 12. https://www. hindawi.com/journals/stni/2013/508485/ 508485.

Bieder, U., Fauchet, G., Betin, S., Kolev, N., Popov, D., 2007. Simulation of mixing effects in a VVER-1000 reactor. Nucl. Eng. Des. 237, 1718-1728. Elsevier.

Böttcher, M., Krüßmann, R., 2010. Primary loop study of a VVER-1000 reactor with special focus on coolant mixing. Nucl. Eng. Des. 240 (9), 2244-2253. Elsevier.

Brun, E., Damian, F., Diop, C.M., Dumonteil, E., Hugot, F.X., Jouanne, C., Lee, Y.K., Malvagi, F., Mazzolo, A., Petit, O., Trama, J.C., Visonneau, T., Zoia, A. (2015) TRIPOLI- ${ }^{\circledR}$, CEA, EDF and AREVA reference Monte Carlo code. In: Proc. Joint International Conference on Supercomputing in Nuclear Applications and Monte Carlo Paris, Nov 2013, SNA + MC 2013, Ann. Nucl. Energy, Vol. 82 August 2015, Pages 151-160.

Chanaron, B., Ahnert, C., Crouzet, N., Sanchez, V., Kolev, N., et al., 2015. Advanced multi-physics simulation for reactor safety in the framework of the NURESAFE project. Ann. Nucl. Energy 84, 166-177. http://dx.doi.org/10.1016/j. anucene.2014.12.013.

Chanaron, B., 2012, NURESAFE, Nuclear Reactor Safety Simulation Platform Description of Work, EU-FP7 project, Grant agreement: 323263.

Chauliac, C., Aragonés, J.-M., Bestion, D., Cacuci, D.G., Crouzet, N., Weiss, F.-P., Zimmermann, M.A., 2011. NURESIM - A European simulation platform for nuclear reactor safety: Multi-scale and multi-physics calculations, sensitivity and uncertainty analysis. Nucl. Eng. Des. 241 (9), 3416-3426.

COBAYA team, 2015, COBAYA4 user's guide, UPM Report, Madrid.

Cuervo, D., Rucabado, G., Sabater, A., Garcia-Herranz, N., 2015. COBAYA4-CTF PinCell Coupling Script for a VVER-1000 Assembly: NURESAFE Technical note. UPM.

Fillion, P., Chanoine, A., Dellacherie, S., Kumbaro, A., 2011. FLICA-OVAP: a new platform for core thermal-hydraulic studies. Nucl. Eng. Des. 241 (11), 4348 4358.

Fillion, Ph., Bergeron, A., Gallo, D., Gregoire, O., Richebois, E., Royer, E., Zimmer, S. 2011. FLICA4 Users Guide. CEA Saclay.

Garcia-Herranz N., Cabellos, O., Aragones, J.M., Ahnert, C., 2002, Performance of the analytic coarse-mesh finite difference method with heterogeneous nodes. In: PHYSOR 2002, Seoul, Korea, October 7-10.

García-Herranz, N, Cuervo, D., Sabater, A., Rucabado, G., Sánchez-Cervera, S., Castro, E., 2017. Multi-scale neutronics/thermal-hydraulics coupling with COBAYA4 code for pin-by-pin PWR transient analysis. Nucl. Eng. Des. 321, 38-47.

Geffraye, G. et al., 2011. CATHARE2 v2.5_2: a single version for various applications. Nucl. Eng. Des. 241 (11), 2011.

Gomez, A., Sanchez Espinosa, V.H., Kliem, S., Gommlich, A., 2014. Implementation of a fast running full core pin power reconstruction method in DYN3D. Nucl. Eng. Des. 274, 86-97.

Hádek, J., Mittag, S., Validation of DYN3D Pin-power Calculations against Experimental VVER-Full-Core Benchmark. In: Proc of Int Conf on Mathematics, Computational Methods and Reactor Physics (M\&C 2009), May 3-7, Saratoga Springs, NY.

Hádek, J., Validation of DYN3D Pin-power Calculation against Experimental Results from the LR-0 Reactor. In: 22nd AER Symposium on VVER Reactor Physics and Reactor Safety, Pruhonice, Czech Republic, October 1-5, 2012.

Hádek, J., Testing of DYN3D nodal and pin-power reconstruction simulation of a VVER-1000 mini-core. In: Proc. 26th Symposium of AER on VVER Reactor Physics and Reactor Safety, October 10-14, 2016, Helsinky, Finland.

Herrero J.J., Jiménez J., Aragonés J. M., Ahnert C., 2009. Performance of whole core pin-by-pin calculations by domain decomposition through alternate dissections in steady state and transient calculations. In: Proc. of Int. Conf. on Mathematics, Computational Methods and Reactor Physics (M\&C 2009), May 3-7, Saratoga Springs, NY. 
Hoehne, T., 2009. CFD simulation of thermal-hydraulic benchmark V1000CT-2 using ANSYS CFX Hindawi Sci. Technol. Nucl. Installations 2009,, 7. http://dx.doi.org/ $10.1155 / 2009 / 835162835162$.

Ivanov, P., 2014. Testing of 2D COBAYA3 nodal solutions for a VVER mini-core in 2, 4 and 8-group diffusion approximation vs. TRIPOLI4 ref solution: Technical note. INRNE.

Jimenez, J., 2009. COBAYA/FLICA4 coupling in Salome 5: NURISP Technical note UPM.

Jimenez, J., Sanchez, V., June 2013, Full-core COBRA-TF input model for VVER MSLB analysis, NURESAFE D14.22b Report.

Jimenez, G., Herrero, J.J., Gommlich, A., Kliem, S., Cuervo, D., Jimenez, J., 2015. Boron dilution transient simulation analyses in a PWR with neutronics/therma hydraulics coupled codes in the NURISP project. Ann. Nucl. Energy 84, 86-97.

Kolev, N.P. et al., 2010. VVER-1000 Coolant transient benchmark Phase II (V1000CT2), Vol. 2, Final Specifications of the VVER-1000 MSLB problem, NEA/NSC/DOC 2006(6) (c) OECD.

Kolev N.P., Aniel, S., Royer, E., Bieder, U., Popov, D., Topalov, Ts., 2010. VVER-1000 Coolant transient benchmark Phase II (V1000CT-2), Vol. 1, Final specifications of the VVER-1000 vessel mixing problem, NEA/NSC/DOC (2007) 22, (c) OECD.

Kolev, N.P., Spasov, I., Royer, E., 2010. VVER Coolant Transient Benchmark: Phase 2 (V1000CT-2), Volume 3: Summary Results of Exercise 1 on Vessel Mixing Simulation, NEA/NSC/DOC (2010) 10, Paris (c) OECD.

Kolev, N.P., Spasov, I., Tzanov, Tz., Royer, E., 2011. VVER-1000 Coolant Transient Benchmark: Phase 2 (V1000CT-2) Volume 4: Summary results of coupled 3D kinetics/core-vessel thermal hydraulics and core-plant MSLB simulation. NEA/ NSC/DOC (2011) 3, Paris (C) OECD.

Kolev N.P., Spasov, I., Todorova, G., 2014. VVER MSLB Specification-Vessel mixing tests and N/TH simulation at the nodal level, NURESAFE D14.11.1 report.

Kolev, N.P., Spasov, I., Zheleva, N., Todorova, G., Petrov, N., Ivanov, P., Mitkov, S. Kamenscic, O., Hadek, J., Vyskocil, L., Jimenez, J., Sanchez, V., Sanchez-Cervera, S., Garcia-Herranz, N., Sabater, A., Cuervo, D., February 2016. Higher-resolution VVER MSLB simulation - Final report, NURESAFE D14.41.

Lozano, J.-A., Garcia-Herranz, N., Ahnert, C., Aragones, J.M., 2008. The analytic noda diffusion solver ANDES in multigroups for 3D rectangular geometry: development and performance analysis. Ann. Nucl. Energy 35, 2365-2374.

Lozano, J.A., Jiménez, J., García-Herranz, N., Aragonés, J.M., 2010. Extension of the analytic nodal diffusion solver ANDES to triangular-Z geometry and coupling with COBRA-IIIc for hexagonal core analysis. Ann. Nucl. Energy 37, 380-388.

Merino, F., Ahnert, C., Aragonés, J.M., 1993. Development and validation of the 3D PWR core dynamics SIMTRAN code. In: Kusters, H. (Ed.), Mathematical Methods and Supercomputing in Nuclear Applications, Vol. 1. ANS-KfK, Karlsruhe, pp. 646-657.

Petrov N., Spasov, I., Kolev, N., Sanchez-Cervera, S., Garcia-Herranz, N., Jan 2015. Nodal level XS library v2 for VVER parameterized for MSLB, NURESAFE D14.25Rev2 report.

Rohde, U. et al., 2016. The reactor dynamics code DYN3D - models, validation and applications. Progr. Nucl. Energy 89, 170-190.

Sanchez, R., APOLLO2 Year 2010, Nuclear Engineering and Technology, Vol. 42, no. 5, October (2010)

Cervera Sánchez, S., Herranz García, N., Herrero, J.J., Cabellos, O., 2014. Optimization of multidimensional cross section tables for few group core calculations. Ann. Nucl. Energy 69, 226-237.

Sanchez-Cervera, S., Garcia-Herranz, N., 2015. On the up-scattering correction in the VVER MSLB compact cross-section library: NURESAFE Technical note. UPM.

Santandrea, S., Sanchez, R., Mosca, P., 2008. A linear surface characteristic approximation for neutron transport in unstructured meshes. NSE 160 (1).

Spasov, I., Kolev, N.P., Donov, J., Sabotinov, L., 2010. CATHARE multi-1D Modeling of coolant mixing in VVER-1000 for RIA analysis. Sci. Technol. Nucl. Installations (open access) 2010,. http://dx.doi.org/10.1155/2010/457094. Hindawi, New York 457094.

Spasov, I., Kolev, N., March 2013. Full core FLICA4 input model for VVER MSLB analysis, NURESAFE D14.22a report.

Spasov, I., Kolev, N.P., Mitkov, S., 2013. CATHARE input model for VVER MSLB simulation, NURESAFE D14.21 report.

Spasov, I., Mitkov, S., Kolev, N., 2014. Sub-channel FLICA4 and COBRA-TF input models qualified for VVER, NURESAFE D14.23 Report.

Topalov Ts., Popov, D., 2004. Plant data from the Kozloduy-6 SG isolation experiments, Technical note, NPP Kozloduy.

Trama, J.C., Overview of TRIPOLI4 v. 7 Continuous Energy Monte Carlo Code. In: Proc. of International Congress on Advances in Nuclear Power Plants, Nice, France, May 2-6, 2011, SFEN Publ, p. 1584.

Toumi, I., Bergeron, A., Gallo, D., Royer, E., Caruge, D., 2000. FLICA-4: a threedimensional two-phase flow computer code with advanced numerical methods for nuclear applications. Nucl. Eng. Des. 2000, 139-155.

Vyskočil L., Simulace míšení v reaktoru VVER-1000 JE Kozloduj pomocí CFD programu Fluent Internal report of ÚJV Řež, a.s. (In Czech language). ÚJV Z 3820 $\mathrm{T}, 08 / 2013$.

Vyskocil, L., 2015. FLUENT rke computed time-dependent core BC for the VVER1000 MSLB benchmark: NURESAFE Technical note. UJV. 